\title{
A MULTI AGENT DECISION TREE ALGORITHM FOR SUPPLY CHAIN MANAGEMENT
}

\author{
${ }^{1}$ C.P.Balasubramaniam, ${ }^{2}$ Dr.A.Edwin Robert \\ Research Scholar, Karpagam Academy of Higher Education, Coimbatore \\ 1sivaanand_cp@yahoo.com \\ Assistant Professor of Computer Applications, Karpagam Academy of Higher Education, Coimbatore \\ 2 edrt.edwin@gmail.com
}

\begin{abstract}
The issue of interest here is the behaviour of decision agents in supply chain management. The study uses a managerial framework to organize supply-related tasks to the behaviour of specification stantiations of decision agents. The reasons why organizations might elect to invest supply chain management responsibilities in decision agents rather than human functionaries are illustrated. Finally, this research presents a final construct for optimal agent-based decision making opportunities. The implication is that a shift of power from humans to computers is shown to bequite effective on technically tractable decision situations.
\end{abstract}

\section{KEYWORDS}

Decision Agents, Information System Development, Decision Making, Supply Chain Management.

\section{ACADEMIC DISCIPLINE}

\author{
Computer Science
}

\section{SUBJECT CLASSIFICATION}

Classification of decision trees using supply chain management

\section{TYPE (METHOD/APPROACH)}

The supply chain organization requires the selection of agents whose cooperationcan ensure the success of the entire supply chain. It is necessary to adopt strategiesthat take into account the uncertainty of the environment in which the agents work.

In fact, the establishment of a supply chain is not a deterministic process. A Multi-Agent Decision Support System for Dynamic Supply Chain Organization 5such as delays in delivery - for example due to an excessive geographical distance of the companies the agents represents, the reliability of a supplier and consequently the failure to meet his commitments could determine a failure for the supply chain. To take into account the uncertainty of the business process, in our system each agent adopts a Bayesian Decision Network (BDN) to represent explicitly considerations about cost-benefits associated with each strategy in the decision-making process.

In our system, each agent can assign a degree of uncertainty to the success orfailure of a particular configuration for a supply chain. To develop its business process, an agent retrieves the information about all the suppliers available to join its own chain and reasons on the collected information then, by means of a BDN, the agent filters the suppliers and retains only those able to organize the best sub-chain. The probabilities of the network may be a priori known or on-line learnt basedon strategies chosen by each agent. In this sense, several strategies can be adopted, especially depending on the type of market. Business decisions can be taken in relation to parameters of convenience, as generally done in case of wide consumer products, or considering other factors such as the prestige, the competitiveness or the brand of the potential suppliers, as happens in a market of luxury or highly differentiated products. Different strategies can be appropriately modeled in the BDN.

\section{INTRODUCTION}

From the viewpoint of management science, managers must rationally allocate the limited resources at the managers' disposal by making optimal decisions that result in the ultimate outcome of profit maximization. Thus, the content of managerial rationality requirements is to make decisions that maximize an organization's benefits. Supply chain management (SCM) is a proven strategic business structure that's goal is to implement organizational decision making

that results in optimal performance. It has gained wide acceptance in recent years because it helps managers make optimal decisions that rationally allocate resources that increasing are supplied by a global network of suppliers. In addition, customer demands for variety, quality, delivery, and speed require the supply chain to operate "slicker" as its performance and cost is

pivotal to overall profit maximization. While ideal rational decision making in SCMis an impossibility when viewed as comprehensive rationality, SCM is a collection of decisions made under the constraints of bounded rationality that can approximate optimal decisions. Supply chain management systems are instantiations of management support systems 
which provide instances of decision technology. They are composed of a set of intelligent decision agents, which interact with other decision agents to plan and execute one or more responsibilities. Decision agents are an "autonomous, goaloriented software process that operates asynchronously, communicating and coordinating with other agents as needed" (Fox et al., 2000).

This paper is organized as follows. First, this research discusses SCM and organizational decision making. It then defines the three levels of organizational decision making and the computer-based constructs that can be used in the optimization of supply chain performance. These levels have been identified in the management literature as strategic level (unstructured), tactical (semistructured), and operational level(structured) decision making(Gorry andMorton, 1971). DDDs and decision agentscan be employed in the tactical andoperational levels of decision making.Specific instantiations of decision agents andDDDs and their references in the literaturewill be outlined and a concluding construct is represented.

\section{LITERATURE SURVEY}

Supply chain management (SCM) is a provenbusiness strategy that's goal is to implementdecision making that results in optimalperformance. Supply chains can exist in bothmanufacturing and service organizations, and they are principally concerned with theflow of products and information betweenthe organizations in the supply chainnetwork, the procurement of materials,transformation of materials into finishedproducts, and distribution of those productsto the end customers. Today's informationdriven,integrated supply chains are enablingorganizations to reduce inventory and costs, add product value, extend resources, accelerate time to market, and retaincustomers. In the last few years,organizations that are supply chaininnovators have migrated from buildingexcellence in its supply chain to making useof the supply chain to create added-value.

\section{PROPOSED WORK}

During the supply chain organization process, each agent can receive an invitation tojoin the chain as supplier and, based on its actual resources, productive capabilitiesand economical convenience, it can decide if joining the chain or no. To collaboratein the chain, the agent can ask other agents for products/services it needs for its ownbusiness process. In this case, it acts as customer and invites other agents to join the chain for satisfying a certain order. In practice, before joining the supply chain, the agent needs to organize a sub-chain for its own business process. Once an agent knows it can join the supply chain, it replies to the invitation informing about its availability and the conditions it wants to impose for being part of the collaboration

(for example price and temporal conditions). Therefore, a supply chain is the result of a set of negotiations among the agents belonging to the same group. To consensus, two different kinds of information flow across the agent network. in figure 2, the up-down information flow represents the invitations sent to agents for being part of the supply chain, while the bottom-up information flow represents the information flowing from suppliers to customer about their conditions to join the supply chain. During the negotiations, all the agents are in competition one each other; their behavior can be oriented to maximizing their business volume constrained by the quality of the final product, their productivity capability and the minimum profit they want to get. The supply chain can be built choosing all the agents that, with the highest probability, could assure the success of the final supply chain and would collaborate to satisfy the final customer's order. In the following, we assume that the entire supply chain can be modeled as a tree; at each level, a sub-tree represents a subchain. In our formulation, at each node of the tree an agent provides a particular goods or service needed at higher levels to provide the product required by the customer. However, the production of this goods/services can require the cooperation of other agents. Therefore it can be necessary to establish a set of collaborations with other agents, i.e. a new sub-chain. The organization of the entire supply chain reduces to recursively organize each sub-chain as showed in figure1. The problem of organizing a supply chain is therefore addressed by dividing it into sub-problems of lower complexity. The entire supply chain can be organized considering sub-optimal solutions at each node of the tree. Whilst in general the solution will not be globally optimal, under the assumption of independence of the sub-tree, the final solution will be optimal. This assumption does not limit the applicability of our system because it is reasonable to assume that at each node of the supply chain independent business processes would be developed.

\section{EXPERIMENAL RESULTS}

To evaluate the performance of the proposed work for SCM, the textile dataset collected from open source. The dataset contains labels, Supplier id, quantity, cost, item id, material, size, quantity, Product Cost and dealer cost values. These are given for the proposed improved $\mathrm{C} 4.5$ algorithm. The obtained results and its performance are measured and compared with existing technique for the input textile dataset.

The classification of this algorithm is viewed in tree structure where the decision tree is classified as

if $x 5<24$ then node 2 elseif $x 5>=24$ then node 3 else 4

if $x 1<3.5$ then node 4 elseif $x 1>=3.5$ then node 5 else 4

if $x 1<3.5$ then node 6 elseif $x 1>=3.5$ then node 7 else 6

class $=4$

class $=5$

if $x 2<2750$ then node 8 elseif $x 2>=2750$ then node 9 else 1

6834 | P a g e

April, 2016 
class $=6$

if $x 2<1100$ then node 10 elseif $x 2>=1100$ then node 11 else 1

class $=3$

class $=1$

if $x 9<6925$ then node 12 elseif $x 9>=6925$ then node 13 else 2

class $=3$

class $=2$

Figure 2: Classification of Proposed Technique Viewed In Tree Structure

\begin{tabular}{|l|l|l|}
\hline Performance Measures & Improved C4.5 for SCM (\%) & $\begin{array}{l}\text { Fuzzy Classification For SCM } \\
(\%)\end{array}$ \\
\hline Accuracy & 93.9 & 90.1 \\
\hline
\end{tabular}

Table 1: Comparison Table for Accuracy

\section{FIGURES}

Figure 1 shows an example of decision network used by each customer agent toorganize its own sub-chain.

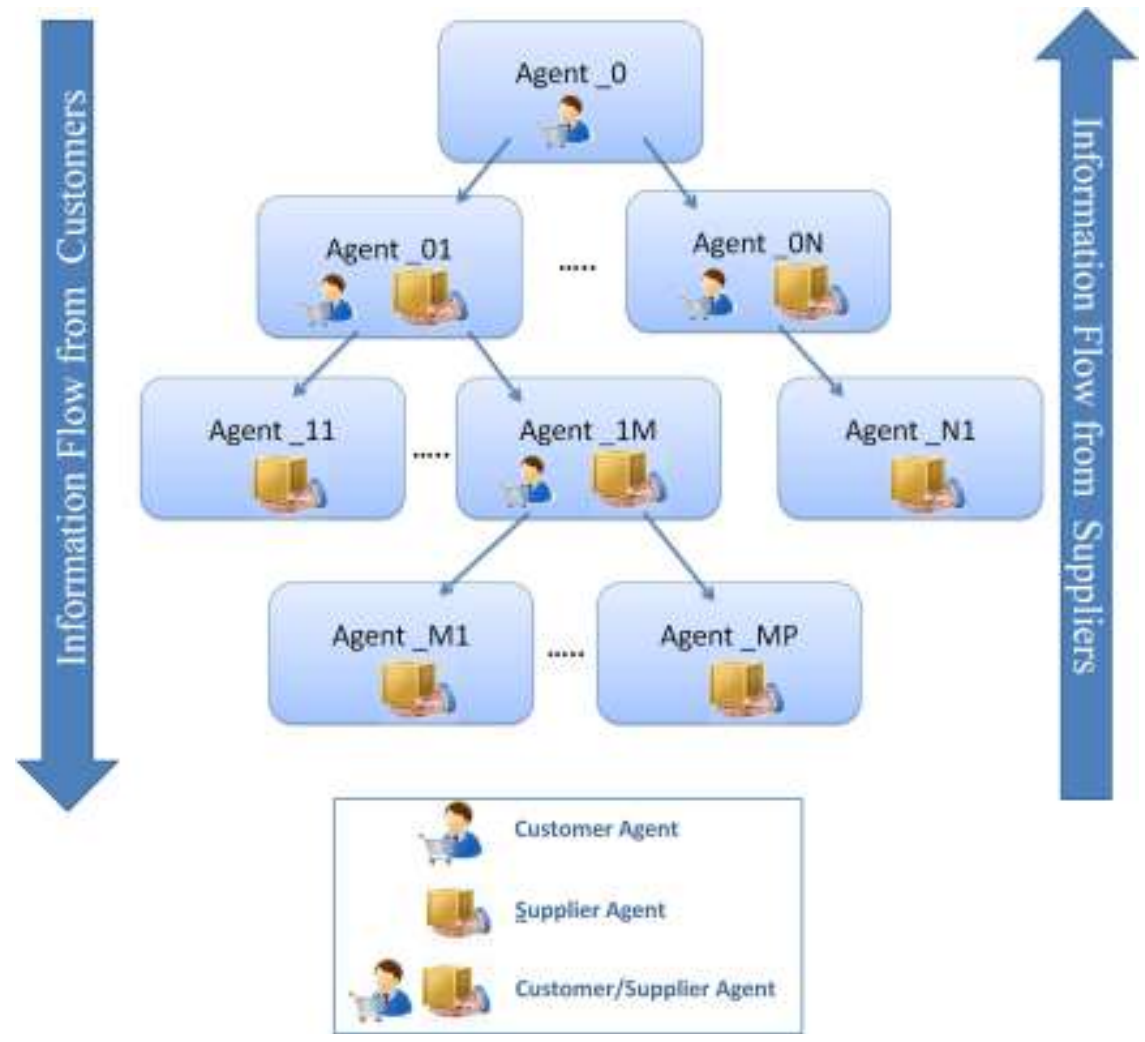

FIGURE 1 :Classification of Agents 


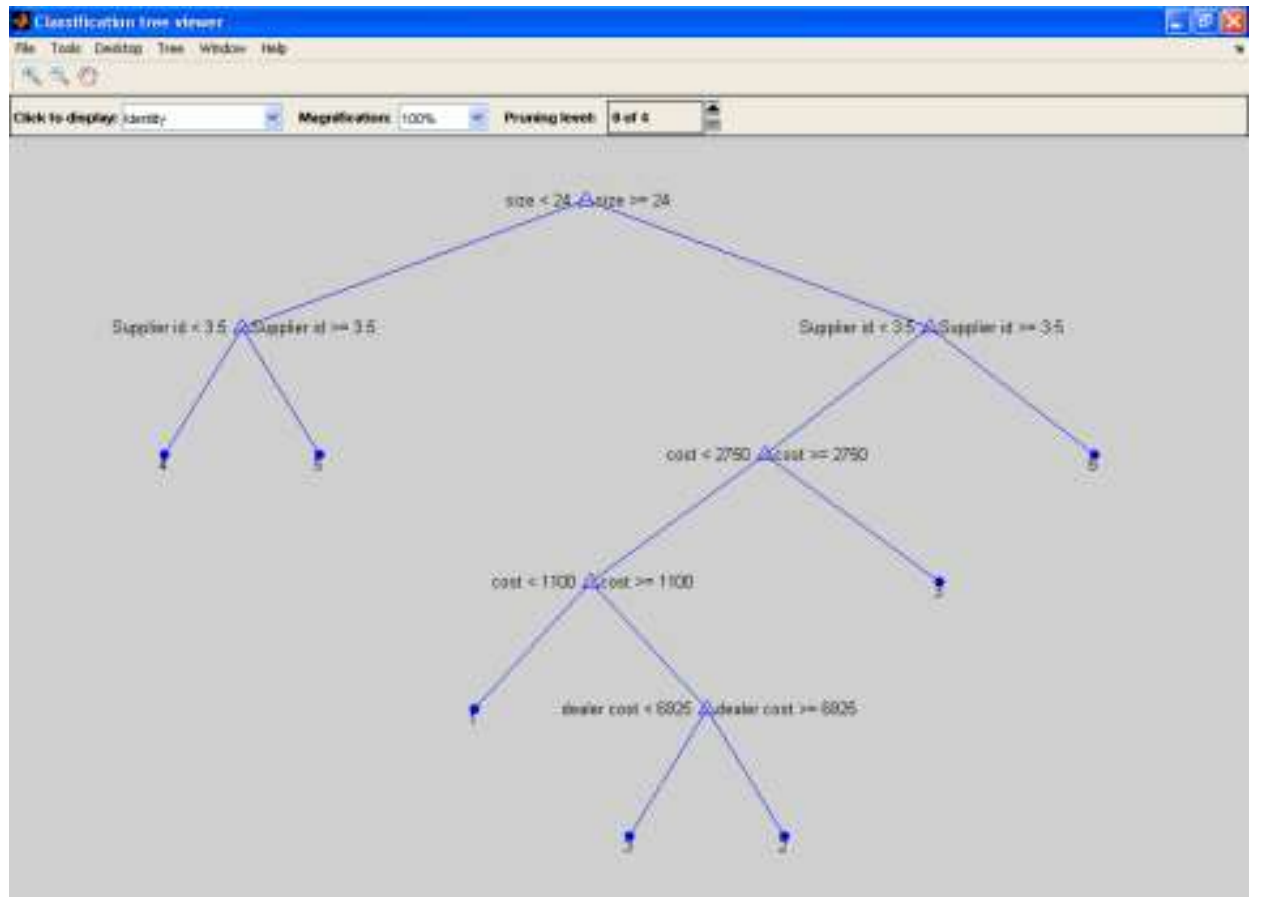

FIGURE 2: Classification of Proposed Technique Viewed In Tree Structure

\section{ACKNOWLEDGMENTS}

Our thanks to the experts who have contributed towards development of the template.

\section{REFERENCES}

I Breiman, L., Friedman, J., Olshen, R., and Stone, C. (1984): Classification and Regression Trees, New York; Chapman and Hall.

II Kass, G. (1980): An exploratory technique for investigating large quantities of categorical data, Applied Statistics, 29, $119\{127$.

III Magidson, J. (1993): The use of the new ordinal algorithm in CHAID to target protable segments, The Journal of Database Marketing, 1, 29\{48.

IV Quinlan, J. R. (1986): Induction of Decision Trees. Machine Learning 1, 1 (Mar. 1986), 81-106.

V Claude Shannon and Warren Weaver in their publication model of communication in 1949

VI Berry, M.J.A., and Linoff, G., Data Mining Techniques :For Marketing, Sales, and Customer Support, WileyComputer Publishing (1997)

VII Braun, Han I.,, and Chandler, J., "Predicting Stock MarketBehavior Through Rule Induction An Application of theLearning- From- Example Approach", Decision Science,18 (1987)

415-429

VIII Breiman, L.J. Friedman, J., Olshen, R. A., and Stine, C. J.,Classification and Regression trees, Beltmont, Wadsworth,(1984).

IX Cronan, T., Glorfeld, L., and Perry, L., "Production SystemDevelopment for Expert Systems using a Recursivepartitioning Induction Approach : An Application to Mortgage, Commercial and Consumer Lending", DecisionScience, 22 (1991) 812-845.

X Johnon, D.E., Oles, F.J., Zhang, T. and Goetz, T., "ADecision Tree Based Symbolic Rule Induction System forText Categorization", IBM System Journal, 41.3 (2002)428-437. 


\section{Author' biography with Photo}

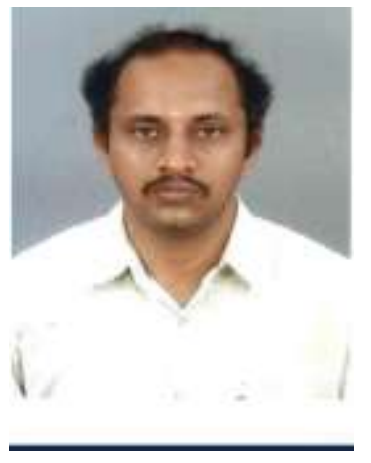

\section{C.P.Balasubramaniam,}

Part time research scholar,

Department of computer science,

Karpagam university,

Ciombatore.

Email :Sivaanand cp@yahoo.com

Contact number : 9788872930 